\title{
An Adoption Framework for Mobile Commerce
}

\author{
Per E. Pedersen \\ Agder University College
}

\begin{abstract}
Most often, technological explanations are given of Europe's slow adoption of mobile commerce. When seeking non-technological explanations, diffusion models provide aggregated explanations of adoption processes while adoption models suggest explanations limited to supply side or demand side issues separately. In this paper, an adoption framework is suggested that integrates technological, business strategic and demand side requirements for adoption of mobile commerce end-user services. The framework may be used as a research framework for integrating adoption models and adoption study findings in mobile commerce. It may also be used as an evaluation framework for network operators and other participants in the mobile commerce value chain when developing their services and business models.
\end{abstract}

\section{INTRODUCTION}

In a much sited Ovum-report, the number of mobile commerce users is expected to be more than 500 million in 2005 , and the corresponding value of mobile commerce transactions is expected to be more than US\$200 billion (Davidson et al., 2000). This is one of several recent analyst reports that have contributed to the hyped expectations of what may be gained by giving mobile terminal users access to the Internet. We define mobile commerce as electronic commerce when accessing the Internet using mobile terminals. This implies using mobile data services. While the data-based traffic volume is now larger than the voice-based volume in fixed networks, traffic volumes in mobile networks are still primarily voice-based. In Scandinavia, SMS has contributed to increased data traffic, but other data-based services, such as WAP have so far not been very successful. Often, technological explanations such as low bandwidth and interface limitations, are given for the slow adoption of these services. Technologies like HSCSD and GPRS may overcome many of these limitations, but our suggestion is that non-technological explanations are necessary as well. The case of the Japanese I-mode service is often used to 
illustrate that other reasons for the slow adoption must be addressed. Initially, the bandwidth, interface and service functionalities of the I-mode service were very similar to the European WAP-based services of today. Still, more than 19 million Imode subscribers are now using the service ${ }^{63}$. When confronted with this success, European operators often refer to non-technical explanations, such as cultural differences between Japanese and European mobile phone users, different pricing schemes, and different user experiences due to the packet switching technology of the I-mode service (Stiehler and Wichmann, 2000). Consequently, technological and non-technological explanations should be combined to understand Europe's slow adoption of mobile Internet, and consequently of mobile commerce.

To better understand the integration of technical and non-technical adoption requirements, we suggest an adoption framework specifying both supply side and demand side requirements for adoption. The framework is not a theory, but a framework for integrating different theories and models into an understanding of the technological and non-technological requirements of adoption. As such, it serves two purposes. First, it may be used as a research framework for integrating technological, business strategic and behavioral studies of mobile commerce and mobile end-user service adoption. Second, it may be used by network operators and other participants in the mobile commerce value chain as a framework for modeling and predicting end-user service adoption. The framework divides adoption requirements into supply and demand side requirements. Supply side requirements are further split into technological and business strategic requirements. Demand side requirements are further split into individual, social and cultural requirements.

In the next section, the framework is presented. The rest of the paper elaborates on the technological, business strategic and demand side requirements in sections 3 , 4 , and 5, respectively. In the final section we conclude on how the framework can be applied by operators and other suppliers in the mobile commerce value chain to understand the particular adoption requirements they face. Finally, some suggestions on how we plan to apply, refine and further develop our framework are presented.

\section{THE ADOPTION FRAMEWORK}

The simplest adoption models focus on technological supply side issues only, and introduce a phase model of technology development. These phase models are applied to predict when certain technological requirements will be met and a enduser service may be introduced (e.g. Müller-Versee, 2000; James, 2000). Predicting what happens after the end-user service has been introduced is typically left to aggregated diffusion models (Mahajan and Muller, 1990; Rogers, 1995). Diffusion

63 As of February 18, 2001. Continuously updated figures are available at http://www.nttdocomo.com/i/inumber.html. 
models predict adoption as an S-shaped function of time after the service has been introduced. The S-shaped adoption rate was originally explained by a simultaneous communication of innovations using two channels - personal communication and mass media (Rogers, 1995). The continuous diffusion function may also be replaced by a discontinuous, phase transition model (e.g. Loch \& Huberman, 1999).

The three terms diffusion-, adoption- and innovation models are often used interchangeably in studies of technology adoption. While diffusion models are models of the aggregate rate of adoption of a technology or service, adoption models try to specify the conditions and requirements for adoption at the industry, firm and individual level (Frambach et al. 1998). Even though such requirements are found at both the supply side and at the demand side, adoption models typically focus the demand side requirements and demand side explanations of adoption (Frambach, 1993). Recently, models integrating supply and demand side explanations of adoption have become more common (e.g. Frambach, 1993). Innovation models may apply elements of both diffusion and adoption models but are often more practically oriented. They go beyond pure adoption, and also seek to explain how technology and services are used, how use spreads in and across organizations, and how the use of services turns into standard routines. In these models, the characteristics of the technology, user context and users are important. Rogers (1995) discuss some of the relevant characteristics of the technology, such as relative advantage, compatibility, complexity and testability. These are all supply side characteristics. At the demand side, users are often categorized as early adopters, early majority users, late adopters etc. The classic innovation study typically contrasts the technology requirements of different user categories to explain the adoption process a posteriori.

The framework presented here is best classified as an adoption model framework. It specifies important adoption requirements at the industry, firm and individual level at both the supply and demand sides. Figure 1 shows the adoption framework and its supply- and demand sides. The supply side is organized as a value chain to illustrate that the supply side involves a large set of technology-, serviceand application suppliers as well as the interactions among these participants. For example, adoption of mobile commerce requires that the technology platforms and service technologies of these participants are widely adopted among service providers and application developers.

Figure 1. The adoption framework

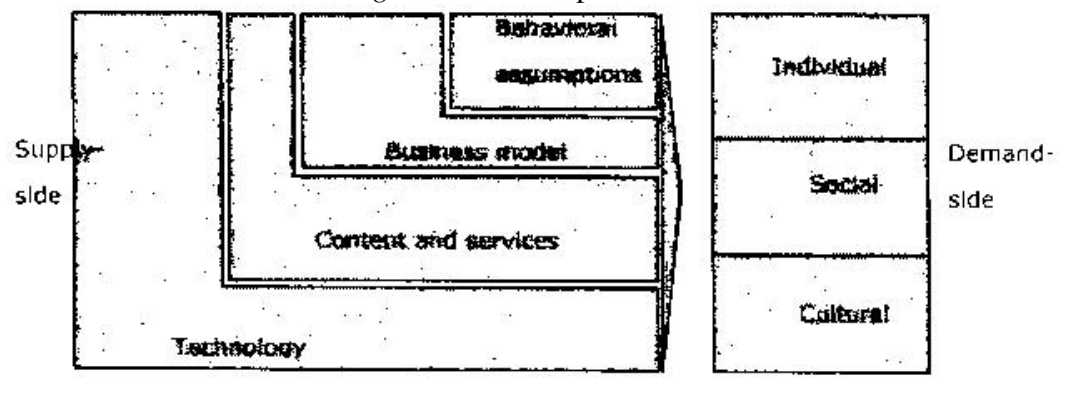


The demand side may not be studied from the perspective of the user as an individual only, but the users' social and cultural context must also be included. For example, the social interaction among users are important not only to understand how mobile commerce innovations are communicated among end-users, but also to understand how these services are adopted to maintain and coordinate social networks.

At the end of the supply side of the value chain, service providers must deliver end-user services that are in demand. Specifying the requirements for introducing these end-user services start with specifying the technological requirements for producing and distributing these services. Next, technology is used by application developers to turn content, network services and related services into end-user services that users are willing to pay for. The infrastructure necessary for this production and distribution, however, is not only purely technological. It also contains the business models and behavioral assumptions of all participants in the value chain. For example, end-user services in mobile commerce gain from direct network effects that turn into indirect network effects in the value chain (Gupta et al., 1999). Consequently, the principles used when these participants define their business models must take indirect network effects into consideration. Similarly, the behavioral assumptions held by these participants must include considerations of how direct network effects operate and affect service demand. To emphasize the importance of these issues, our framework separates technological and business related issues on the supply side of the mobile commerce value chain, and we discuss these issues in sections 3 and 4 respectively.

Most adoption models applied to the demand side rely on a specific user model, such as the Davis' technology acceptance model (TAM) (Davis, 1993) or the theory of planned behavior model (TPB) of Ajzen and Maddon (1986). These models provide a technology-user perspective on the adoption process only. However, technology, and in particular end-user services, are always applied in a richer context. For communication technologies, this context is represented by the endusers' social and cultural situation. For example, end-user services in mobile commerce are applied in the social context of families and groups of close friends. To fully understand the importance of such contexts, models and studies of adoption must apply multiple, context sensitive models. In section 5, we suggest three context sensitive models that may be applied simultaneously to understand the demand side requirements for adoption of mobile commerce end-user services.

\section{TECHNOLOGICAL REQUIREMENTS}

Even though satisfying the technological requirements of adoption is not enough, these requirements are fundamental to the production and distribution of end-user services in mobile commerce. Our framework splits the technological 
requirements into technology and service requirements. The technology requirements include the requirements of network technologies, terminal technologies and service technologies necessary for the production and distribution of end-user services. New network technologies are introduced to produce higher bandwidth and provide a platform for new services like location based services or always-on functionality. Even though technologies like Enhanced GPRS (EDGE) and UMTS are important in providing such functionality, we do not yet know very much about their performance in real time settings (e.g. Lopez, 2000). While waiting for these technologies, non-regulated technologies like e.g. IEEE802.11b are adopted by professional users to satisfy their bandwidth and always-on requirements. Mobile commerce will not be adopted unless reasonably priced, functional terminal technologies are available. A long history of terminal delays, lack of flash-upgradeable components and a variety of terminal operating systems make end-users fear being locked in. For example, a standards battle is fought between mobile terminal operating system providers like Symbian (Epoc), Palm (PalmOS) and Microsoft (WindowsCE/PocketPC). Similar standards battles are found between providers of important service technologies necessary to produce and distribute mobile commerce end-user services. Examples are the standards battles between content and presentation format standards (e.g. WML, XHTML, cHTML and $\mathrm{MeXe}$ ) and between providers of public key infrastructure service technology (e.g. Entrust and Baltimore).

The service requirements include the network services, content services, and related services necessary for the production and distribution of end-user services. Because there has traditionally been a difference between the telecom and computer software industries in their definition of the service concept (UMTS-Forum, 2000a), the relationship between basic services, applications and end-user services is illustrated in figure 2 .

\begin{tabular}{|c|c|c|}
\hline \multicolumn{3}{|c|}{ End-user services } \\
\hline & Apphications \\
\hline Network services & Content services & Related services \\
\hline Technolagies & Content & Intrastructure \\
\hline
\end{tabular}

Figure 2. Network-, content- and related services

As shown in figure 2, technologies are exposed to application developers through network services and content is exposed to application developers through content services. End-user services are services that are in demand and consequently, end-users pay for. To design these services, application developers often apply related services as well. An example of this is the provision of location 
based product catalogs. Location services are made available to application developers by the network operators' using location technology. Product, vendor numbers and map information are available to application developers by content providers as a content service. To design the end-user service, the application developer may also rely on related services, like for example a payment service provided by a bank. While operators traditionally have been paid directly for their network services (like data and voice), mobile commerce will require a completely different service and payment model. Standards battles, like those referred to above, are also fought between providers of network-, content-, and related services. As an example, consider the battle of banks, operators and network technology suppliers to determine standards for mobile payments (see Dahlström, 2000). In addition to resolving standards battles, there are other service requirements that must be met for widespread adoption of mobile commerce. For example, consider the problem of service roaming. As long as operators' payment models were based upon network services, the number of services was small, and roaming and interconnection issues were easily resolved. In 3G, end-users will require end-user service roaming, but this will require complex roaming agreements and solutions among operators.

The technological requirements are only met when the three categories of technical and the three categories of service requirements are simultaneously met. No single participant in the mobile commerce value chain controls these technologies and services. Thus, no single participant can set and define the necessary standards to guarantee compatibility across the necessary technologies and services. Even though many cross-organizational initiatives have been taken to guarantee the necessary openness and compatibility of technologies and services (e.g. Symbian for terminal operating systems, MET for payment services, and Radicchio for PKI infrastructure), standards battles are still fought at all stages of the mobile commerce value chain. Generally, there is a danger that these standards battles obstruct common agreement on compatibility, and as a result, slow down the adoption of mobile commerce (see Shapiro and Varian, 1999).

Understanding the interaction of technology and services in mobile commerce is not straight forward. Consequently, modeling this interaction in an attempt to predict when the technological requirements of adoption will be met is even less straight forward. However, recently several theoretical contributions have been made on how complementarities, standards battles and network effects can be taken into account when modeling the complex relationships of technologies and services (see Schoder, 2000 for examples). These theories may be operationalized and fit into our adoption framework in an attempt to model the technological requirements for adoption. 


\section{BUSINESS STRATEGIC REQUIREMENTS}

Even if the technological requirements for adoption of mobile commerce are met, this is not sufficient for widespread adoption. For example, lack of critical mass may occur at both the supply and demand side. At the supply side, critical mass also means sufficient diversity of end-user services for selection processes to determine what kind of end-user services will finally be adopted. To reach supply side critical mass, the business models of mobile commerce value chain participants must support service diversity. Furthermore, a critical mass of application developers and service providers must adopt the technology and service platforms necessary to develop end-user services. In the value chain participants' choice of business models, the business strategic foundation for widespread adoption of mobile commerce is laid.

Even though there are many definitions of what is meant by a business model (Timmers, 2000, Mahadevan, 2000), we concentrate on two major strategic decisions that participants in the mobile commerce value chain must make - the boundary decision and the cooperation decision. The boundary decision is the clarification of the participant's horizontal and vertical integration in the value chain (Williamsson, 1985). In our perspective, the boundary decision includes decisions on integration direction, integration, strategy, integration model and integration form. By integration direction we mean that for all its activities, the firm must decide whether it will expand or contract horizontally or vertically. By integration strategy we mean that for all its activities, the firm must chose the basis for its scale economy - traditional scale or scope. By integration model we mean that the firm must decide how transactions that are not within hierarchical control will be governed. In transaction cost economics, this is termed governance form. Finally, the combination of integration direction, strategy and model is not arbitrary. Combinations of the three dimensions constitute specific integration forms. In traditional electronic commerce a set of successful integration forms can be identified (e.g. Pedersen and Methlie, 2001), and it is likely that the same will be the case in mobile commerce. To illustrate the boundary decision, consider a network operator's situation. The operator must decide if it should take control over functions otherwise performed by other upstream or downstream participants in the value chain, or if it should take control over other operators or customers in a horizontal direction. It must also decide how different markets and customers should be served in focused or undifferentiated manners. For the transactions it does not control hierarchically, the right integration model must be chosen for each transaction. For example, some transactions may be controlled by referring customers to a different service provider, while other transactions may be controlled by licensing and agent agreements with other providers. Typically, the more vertical the integration direction, the more undifferentiated the integration strategy, and the more hierarchical the integration model of the operator, the more the operator's business 
model equals the operator model used in $2 \mathrm{G}$ networks. In $3 \mathrm{G}$ networks, this business model may not support the necessary diversity of end-user services, and consequently slow the adoption of mobile commerce.

The cooperation decision is choosing what cooperation and revenue sharing models should be used. In transaction cost economics, the cooperation model is often treated as a special governance form, but in industries with strong direct and indirect network effects, the cooperation decision may require separate treatment (Antonelli, 2000, Gulati et al., 2000). It is assumed that due to reduced coordination cost, increasing service complexity, and standardization, the mobile commerce value chain will become more like traditional electronic commerce value chains. This implies a more disintegrated model will replace the traditional "walled garden" model of the 2G networks (Barnett et al., 2000, UMTS-Forum, 2000b). In traditional electronic commerce, the observed multiplexity of cooperation models goes far beyond what should be expected when analytically treating cooperation models as governance forms only. Syndication models, licensing agreements and affiliate programs are only some of the cooperation models found in traditional electronic commerce. Generally, the observed cooperation models seem to be more open and under less transactional control than what should be expected when analyzing the dyadic relationship of the cooperation partners separately. One of the main reasons is that direct network effects on the demand side translate into indirect network effects in the value chains of complementary goods (Gupta, et al., 1999). In industries of strong network effects, the cooperation model should not be decided by only analyzing the dyadic relationships between producers of complementary goods. For example, operators should not determine how to cooperate with content providers by only investigating complementarity between content and delivery platforms. There may be horizontal indirect network effects among content providers, and the operator must take these effects into consideration when designing their cooperation models. In general, such considerations may result in the choice of more open cooperation models than separate dyadic considerations suggest.

Open cooperation models may be important to take advantage of direct and indirect network effects, but are likely to create revenue sharing problems in mobile commerce. Due to loose coupling of value creation and revenue generation in value chains of complementary goods (Economides, 1998), strong participants may be tempted to use monopoly power to maximize their own revenue while participants in more competitive parts of the value chain are left with little revenue even though their complementary products are extremely important to customer value. To avoid this situation, revenue sharing models may be implemented in value chains with strong indirect network effects. Revenue sharing agreements are not uncommon in telecom, but they are usually based upon an understanding of the importance of direct, and not indirect, network effects. For example, operators have a long tradition of interconnection and roaming agreements. These are horizontal revenue sharing 
models, but it seems much more difficult to create similar vertical revenue sharing agreements. One reason may be that the direct network effects are obvious in horizontal revenue sharing agreements while the indirect network effects from vertical revenue sharing agreements are more concealed.

To understand and study the boundary and cooperation decisions of participants in the mobile commerce value chain, we suggest the application of two theoretical perspectives. Transaction cost theory is fundamental to understanding boundary spanning and the boundary decision. It has previously been applied to understand boundary decisions in traditional telecom value chains (e.g. Brousseau and Quelin, 1996). Recently, it has also been applied to the analysis of boundary decisions in traditional electronic commerce (e.g. Brousseau, 1999, Pedersen and Methlie, 2001). We also suggest that transaction cost theory should be supplemented with theory of increasing returns to understand the importance of network effects. Recently, attempts have been made to refine demand side oriented increasing returns theory to better understand supply side issues, such as indirect network effects and horizontal complementarity (Schoder, 2000, Wendt et al., 2000, Weitzel et al., 2000). This line of research is well suited to help us understand the cooperation decision of participants in the mobile commerce value chain.

\section{DEMAND SIDE REQUIREMENTS}

Demand side adoption is typically studied at the aggregate level using diffusion models (Mahajan and Muller, 1990). Even though the original Bass-model has been refined in recent models, these models have been criticized for treating network effects at the aggregate level only (Schoder, 2000). In our adoption framework, we are more concerned with understanding the individual adoption decisions of individual end-users. We assume that the end-user context defines a set of context specific adoption requirements. To understand these requirements, three different perspectives is suggested here. With each perspective follows specific theories, models and methods. The three perspectives are: 1) The end-user as a technology user; 2) The end-user as a consumer; and 3) The end-user as a network member. In the following, we discuss each of these perspectives and how they may be applied to understanding the mobile commerce adoption requirements of end-users.

Adoption of end-user services in mobile commerce may be treated as technology adoption. Several perspectives have been applied to understand technology adoption from the individual end-user perspective. Among these are the TAM model of Davis (1993) and the TPB model of Ajzen and Maddon (1986). Applying the TAM model means investigating the requirements of end-users regarding utility and user friendliness. However, in the TAM model, utility and user friendliness affect users' attitudes towards services. By including the attitude concept, Davis (1993) stresses the importance of user requirements being based upon perceived utility and user 
friendliness rather than some "objective" measure. When compared to the TPB model of Ajzen and Maddon (1986), the TAM model lacks sufficient consideration of the importance of expectations. For services with strong network effects, the importance of expectations should not be underestimated (Shapiro and Varian, 1998). Two of the main sources of end-user expectations are the communication of expectations by other users and by mass media. Two important issues are raised when applying the TAM model to the adoption of mobile commerce. First, instrumental utility is insufficient to obtain widespread adoption of end-user services. Second, the divergence between communicated expectations and user perceptions may seriously affect end-users' long term attitudes towards these services and slow individual end-user adoption.

Even though the user may be perceived as a technology user, mobile commerce end-user services are applied in a consumer context. Adoption models with a consumer orientation traditionally focus what is termed the "first-purchase decision" (Mahajan and Muller, 1990). These models are well suited for understanding the adoption of individual consumer goods. However, most end-user services in mobile commerce will be integrated services closely related to the consumption of other physical or informational goods. For example, in addition to traditional complementarity, many end-user services in mobile commerce will be added value services suited to serve post decisional phases of the consumer life cycle. Examples of such services are interactive manuals, user-group interaction services and services for the social consumption of goods (e.g. coordinating social restaurant visits or social travel). To understand the adoption processes of these services, traditional decision based models of the "first-purchase decision" should be supplemented with models of the consumers' post-decisional buying behavior (see e.g. Foxall, 1999). Two important issues are raised by this perspective. First, mobile commerce enduser services are not context independent services that will have their separate adoption process. Instead, the adoption of these services will depend upon the adoption of complementary and integrated physical goods and services. Second, consumption context and history will be important in the adoption of mobile commerce. For example, adoption of these services should be treated rather as a transition between stages of increasing consumer sophistication than as "firstpurchase adoption". In this perspective, consumer learning history and stage in the consumer life cycle should be parts of the applied adoption model.

A second consequence of taking the end-user context into consideration is taking the role of end-users as network members seriously. The network perspective is focused in network theories of diffusion (e.g. Valente and Davies, 1999). In these aggregate diffusion theories, the importance of communication between network members and the social position of network members are taken into consideration. Even though these issues are important to understand adoption, they apply equally well to all innovations that are communicated through social networks. It does not focus the unique functionality of mobile commerce end-user services as services for 
mediating and coordinating communication in consumer oriented networks. To understand these functionalities, the different network contexts of individual endusers must be understood. There is no single authoritative typology of networks or social groupings that may be applied to categorize network contexts (Wellmann, 1999). In our framework, we apply a typology of networks with increasing complexity - from the simplest personal and relational networks to the networks of networks. When considering the network member's participation in several networks of different complexity, the importance of mobile end-user services as a mediating and coordinating technology is better understood. For example, end-user services may be applied to maintain the virtual home environment (VHE) of the user across network contexts. They may further be applied to maintain and coordinate network relationships between brands and individual consumers, and they may be applied to coordinate the traditional social networks of families or friends in consumer contexts (Ling and Yttri, 2001). Without taking these different network contexts into consideration, analysts of mobile commerce services may lack a very important explanatory element in their adoption models.

\section{CONCLUSIONS AND FURTHER RESEARCH}

We have proposed an adoption framework that can be used as a framework for integrating adoption theories, models and findings at the supply and demand side of the mobile commerce value chain. It includes the integration of technological, business strategic and demand side requirements for the widespread adoption of mobile commerce. The framework should not be treated as an attempt to integrate or replace traditional diffusion models, but serves three purposes. First, it stresses the integration of technological and non-technological requirements for widespread adoption of mobile commerce. Because both analyst reports and professional evaluations of future adoption of mobile commerce have focused technological requirements, emphasizing the integration of technological and non-technological requirements now seem in order. Second, the framework may be used by researchers of mobile commerce to position their contribution to the understanding of end-user services adoption. It emphasizes that currently, no single diffusion or adoption model can be applied to fully understand the complex adoption requirements of mobile commerce. Finally, the framework may be used by participants in the mobile commerce value chain as a framework for understanding the adoption requirements facing their technologies, network services, applications and end-user services. The suggested theories and models we apply to understand each of the different requirement types may also be used by both researchers and value chain participants to get a deeper understanding of the complexity of the mobile commerce adoption process. 
In our research group we have used the framework to position and direct different research activities into understanding these adoption requirements. From a technological requirement perspective, we have started simulation studies modeling the relationship between network services, content services and related services using dynamic simulation methodology. From a business strategic perspective, we have started refining transaction cost and network effect models into an integrated model of the cooperation model selection process. The model will be applied to descriptive studies of the cooperation models of firms in traditional electronic and mobile commerce. From a demand side perspective, we have started to develop a context specific adoption model of the mobile commerce end-user. This model will be applied to descriptive and experimental studies of mobile commerce end-user service adoption.

\section{REFERENCES}

Ajzen I. and Madden, T.J. (1986). "Prediction of goal-directed behavior - Attitudes, intentions and perceived behavioral control", Journal of Experimental Social Psychology, Vol. 22, No. 5, pp. 453-474.

Dahlström, E. (2000). “The common future of wallets and ATM's? Mobile phones!”, ePSO Newsletter, Vol. 1, No. 1, pp. 5-7.

Davidson, J, Walsh, A. and Brown, D. (2000). "Mobile commerce market strategies". Research report, Ovum Research, March.

Davis, F.D. (1993). "User acceptance of information technology: system characteristics, user perceptions and behavioral impacts". International Journal of Man-Machine Studies, Vol. 38, No. 3, pp. 475-487.

Foxall, G.R. (1999). "Putting consumer behavior in its place: the Behavioural Perspective Model research program”. International Journal of Management Reviews, Vol, 1, No. 2, pp. 133-159.

Frambach, R.T. (1993). "An integrated model of organizational adoption and diffusion of innovations. European Journal of Marketing”, Vol. 27, No. 5, pp. 22-41.

Frambach, R.T., Barkema, H.G., Nooteboom, B. and Wedel, M. (1998). "Adoption of a service innovation in the business market: an empirical test of supply-side variables". Journal of Business Research, No. 41, pp. 161-174.

Gupta, S., Jain, D.C., and Sawhney, M.S. (1999). "Modeling the Evolution of Markets with Indirect Network Externalities: An Application to Digital Television". Marketing Science, Vol. 18, No. 3, pp. 396-416.

James, U. (2000). "Introductory $3 G$ Presentation." Presentation held at Nokia 3G Business Seminar, New York, June.

Ling, R. and Yttri, B. 2001. "Nobody Sits at Home and Waits for the Telephone to Ring: Micro and Hyper-Coordination Through the Use of the Mobile Telephone". Forthcoming in J. Katz and M. Aakhus (eds.), Perpetual Contact, Cambridge: Cambridge University Press.

Loch, C.H. and Huberman, B.A. (1999). A punctuated-equilibrium model of technology diffusion. Management Science, Vol. 45, No. 2, pp. 160-177. 
Lopez J.R. (2000). “Implementing GPRS Services”. Presentation held at the Nokia Mobile Internet Conference, Prague, November 22-23, 2000.

Mahajan, V. and Muller, E. (1990). "New product diffusion models in marketing: A review and directions for research". Journal of Marketing, Vol. 54, No. 1, pp. 1-27.

Mahadevan, B. (2000). "Business Models for Internet based E-Commerce: An anatomy". California Management Review. Vol.42, No.2, pp. 55-.

Müller-Versee, F. (2000). "Mobile Commerce", Research Report, Durlacher Research Ltd.

Pedersen, P.E. and Methlie, L.B. (2001). "Integrators" business models in electronic markets". Forthcoming in Magma, Vol. 4, No 1 (in Norwegian).

Rogers, E.M. (1995). "Diffusion of innovations" (4. ed.). New York, The Free Press.

Shapiro, C. \& Varian, H. (1999). "Information rules”. Boston, MA: Harvard Business School Press.

Stiehler, A. and Wichmann, T. (2000). "Mobile Internet in Japan - lessons for Europe ?". ePSO Newsletter, Vol. 1, No. 2, pp. 13-15.

Schoder, D. (2000). "Forecasting the success of telecommunication services in the presence of network effects". Information Economics and Policy, Vol. 12, No. 2, pp. 181-200.

Timmers, P. (2000). "Electronic commerce. Strategies and models for business-to-business trading”. Chichester, Wiley.

UMTS-Forum (2000a). "The UMTS Third Generation Market - Structuring the Service Revenues Opportunities". UMTS.Forum Report no. 9, UMTS-Forum, September

UMTS-Forum (2000b). "Shaping the Mobile Multimedia Future - An Extended Vision from the UMTS Forum". UMTS.Forum Report no. 10, UMTS-Forum, September.

Valente, T. W. and Davis, R.I. (1999). "Accellerating the diffusion of innovations using opinion leaders". The Annals of the American Academy of the Political and Social Sciences, Vol 566, November, pp. 55-67.

Weitzel, T., Wendt, O., and Westarp, F. v. (2000). Reconsidering Network Effect Theory. Proceedings of the ECIS 2000: European Conference on Information Systems, July, Wien.

Wellman, B. (1999). The Network Community: An Introduction to Networks in the Global Village. I Wellman, B. (red.), Networks in the Global Village, pp. 1-47. Boulder, CO, Westview Press.

Wendt, O., Westarp, F.v., and Konig, W. (2000). Diffusion processes in markets for network effect goods - Determinants, simulation model, and market classification.

Wirtschaftsinformatik, Vol. 42, No. 5, pp. 422 (in German).

Williamson, Q. (1985). “The economic institutions of capitalism: Firms, markets, relational contracting”. New York: Free Press. 